\title{
Dificuldade de aprendizagem e saber idealizado no outro
}

\author{
Crístia Rosineiri Gonçalves Lopes Corrêa* \\ Faculdade de Educação, Universidade Federal de Juíz de Fora. Juíz de Fora, MG, Brasil
}

Resumo: $\mathrm{O}$ artigo discute, a partir da abordagem psicanalítica de Freud e Lacan, a relevante problemática das dificuldades de aprendizagem quando se apresentam na vertente sintomática. Argumenta que de um lado a aprendizagem se sustenta na suposição de que o Outro sabe, mas, de outro, podemos verificar nos quadros de dificuldade de aprendizagem vicissitudes que colocam em questão a relação do sujeito com o saber e que nos conduzem para outra dimensão dessa problemática do estatuto do saber no Outro. Trata-se nesse campo somente de um Outro que não sabe ou pode emergir também um Outro cujo saber é excessivamente idealizado? Nesse sentido, o artigo trata da dimensão do Ideal presente nas dificuldades de aprendizagem.

Palavras-chave: dificuldade de aprendizagem, inibição, ideal do ego, Sigmund Freud (1856-1939), Jacques Lacan (1901-1981).

\section{Introdução}

No campo educacional, a dificuldade de aprendizagem, assim como a indisciplina dos alunos, vem sendo denominada "fracasso escolar". Este fenômeno atinge cerca de $50 \%$ a $70 \%$ das crianças e adolescentes encaminhados aos serviços públicos de saúde (Cabral \& Sawaya, 2001).

Nesse contexto, além de outras leituras, como as teorias sociais, políticas e econômicas e déficits orgânicos e cognitivos dos sujeitos para explicar o surgimento das dificuldades de aprendizagem, a Psicanálise surge como uma alternativa capaz de lançar luz sobre manifestações sintomáticas que não são explicadas somente por esses determinantes e que restam enigmáticas. A dificuldade de aprendizagem em sua dimensão de um sintoma, como será abordada nesse presente artigo, pode se manifestar por meio de inúmeras e variadas queixas, tais como, hiperatividade/desatenção, dificuldade de memória e vários outros sintomas.

Embora não possamos generalizar reivindicando que todas as dificuldades de aprendizagem concernem à dimensão sintomática, esse tipo de quadro é muito frequente na clínica infantil. A partir da Psicanálise, esse tipo de quadro pode ser visto sob outra abordagem que pode introduzir uma novidade em relação às referidas leituras, na medida em que o presente artigo ancorado na Psicanálise de Freud e Lacan se propõe a investigar a dimensão do Ideal na dificuldade de aprendizagem enquanto sintoma. Ademais, o presente artigo se propõe a investigar se nessa problemática que põe em xeque a relação do sujeito ao saber no Outro, além de vicissitudes, como a falta de suposição de saber no Outro, encontro do sujeito com um saber no Outro que ele preferiria não saber, encontro com um

* Autora correspondente: crlopes2001@yahoo.com.br
Outro que não se faz fiador e não lhe responde, pode também ocorrer o encontro com um Outro que sabe demais, possibilitando um desdobramento da leitura psicanalítica dessa questão.

\section{Um recorte sobre uma possível leitura da dificuldade de aprendizagem na primeira tópica freudiana}

Freud (1905/1996a) reivindica que o primeiro surgimento da vida sexual da criança, entre os três e os cinco anos, apresenta como um dos resultados a atividade investigatória desse sujeito, que não é outra coisa senão sua curiosidade sexual. De acordo com Freud, são significativas as relações da pulsão de saber ou de investigar com a vida sexual, dado que a Psicanálise revelou a atração precoce exercida nessa pulsão pelos mistérios sexuais.

Nesse sentido, de acordo com Freud, contrariamente ao que o senso lógico possa afirmar sobre isso, no fundamento da atividade investigatória do sujeito infantil não encontramos interesses teóricos, e sim práticos, como o medo da perda do amor e dos cuidados, introduzido pelo nascimento ou pela suspeita da chegada de um irmão. É esse interesse prático que toca em seu narcisismo que põe em marcha a investigação do enigma colocado pela chegada concreta ou fantasiada de um bebê. Inclusive, nesse ponto, Freud institui esse enigma em um lugar privilegiado no sentido de outorgá-lo como o problema original do qual a criança se ocupa, que abrirá para ela as portas de sua atividade investigatória. Segundo Freud, o problema colocado pela diferença sexual vem "só depois". Para esse enigma que circunscreve a origem dos bebês são concebidas soluções anatômicas das mais variadas espécies: "eles sairiam do seio, ou se recortariam do ventre, ou o umbigo se abriria para deixá-los passar" (Freud, 1905/1996a, p. 184). Abertas 
as portas da atividade investigatória, todo o campo da sexualidade desperta a curiosidade no sujeito infantil. Entre outras coisas, as crianças passam a se ocupar, por exemplo, com o problema de saber o que é ser casado, e com isso, em que consiste a relação sexual.

De acordo com Freud (1908/1996b), são três os destinos para tal investigação sobre a sexualidade. A inibição neurótica é o primeiro. Nessa vicissitude, o destino da sexualidade e o da investigação serão os mesmos, permanecendo inibidos a curiosidade e o desejo de saber. A inibição deste último termina por limitar a atividade intelectual ao longo da vida. Aqui, também pode ocorrer uma inibição intensa do pensamento pela ação educativa.

A compulsão pelo saber é o segundo destino. Nesse mecanismo, ocorre o escape da atividade intelectual em relação à operação de recalque. No entanto, tal atividade intelectual permanece sentenciada à repetição do fracasso das pesquisas sexuais. Qualquer investigação pode ser comprometida por infindáveis ruminações. De acordo com Nezan (2006), Freud afirma que, após o fim das investigações sexuais infantis, as atividades investigatórias de cunho sexual emergem do inconsciente como atividade de pesquisa de caráter compulsivo, de forma distorcida e não livre e tornando o pensamento sexualizado. Dentro dessa problemática, a pesquisa se tornará uma atividade de valor sexual, e a intelectualização tomará o lugar da satisfação da sexualidade.

A sublimação constitui a terceira alternativa para o destino da investigação sobre a sexualidade. Nesse processo, ocorre o escape da pulsão sexual em relação à operação de recalque, tomando lugar como avidez de saber. Nessa modalidade, ocorre a desvinculação da libido, que teve êxito em escapar da operação de recalque, em relação aos objetos originais da investigação sexual infantil, ficando, assim, tal pulsão a serviço dos fins intelectuais. $\mathrm{Na}$ leitura freudiana, essa possibilidade constitui a modalidade mais favorável aos interesses intelectuais, na própria medida em que a operação de recalque subtrai somente o sexual, isto é, dessexualiza o pensamento, conferindo, por conseguinte, o caminho aberto para a dimensão intelectual.

Freud irá abordar a sublimação, a qual tem o período de latência - fase compreendida entre o quinto ano de vida e a puberdade - como momento inaugural, sendo a latência sexual infantil o período no qual acontece o desvio da energia sexual para outras finalidades, como a intelectual. O mecanismo da sublimação seria, então, o processo de desvio das forças pulsionais sexuais para novos objetos, tendo como fundamento a renúncia pulsional. De acordo com Mendes (2011), na sublimação, o sujeito deixa a referência à satisfação sexual direta e passa a ter de se haver com ela em sua dimensão "impossível", no que esse impossível da satisfação em jogo na pulsão encontra no processo sublimatório sua possibilidade de plena manifestação, "pois a sublimação revela a estrutura do desejo humano como tal, ao evidenciar que, para além de todo e qualquer objeto sexual, esconde-se o vazio da Coisa, do objeto enquanto radicalmente perdido" (Mendes, 2011, p. 58).

O processo de sublimação é assim descrito: os impulsos sexuais, por derivarem de zonas sexuais perversas, despertam sentimentos desagradáveis, que produzem forças psíquicas opostas. Trata-se de impulsos reativos que 'a fim de suprimir esse desprazer, constroem barreiras mentais da repugnância, da vergonha e da moralidade'. Haveria então uma associação entre a sublimação e a pulsão de saber, ou de pesquisa, entre os 3 e 5 anos de vida. Essa pulsão estaria ligada, por um lado, à pulsão de domínio, da qual seria uma forma sublimada, e por outro lado, à escopofilia (Coutinho lembra que a palavra se origina do grego e significa o ato de ver, de examinar). (Mendes, 2011, p. 58).

Assim, durante o período de latência total ou apenas parcial, conferido pela operação de recalque constituído pelo núcleo da sexualidade perversa e polimorfa presente na infância e posteriormente sucumbida à amnésia infantil, erigem-se as forças anímicas que, mais tarde, surgirão como entraves no caminho da pulsão sexual e estreitarão seu curso à maneira de diques, como o asco, o sentimento de vergonha, as exigências dos ideais estéticos e morais (Freud, 1905/1996a, p. 167), com a intenção de adiar a função reprodutiva para o momento da maturidade genital. Nessa direção, Freud concebe o período de latência sexual da infância como compreendendo a força inibitória na qualidade de uma força psíquica, um dique que constitui um obstáculo à pulsão sexual. A operacionalidade dessa força inibitória visa ao refreamento da pulsão sexual, "que escapa ao processo de sublimação" (Santiago, 2005, p. 124), reforçando essa sublimação, consolidando o processo de inibição da pulsão quanto a seu objetivo, possibilitando a dessexualização do intelectual e, por conseguinte, o desenvolvimento cognitivo da criança. Com isso, Freud deflagra que a inibição como um dado de estrutura é por excelência a inibição sexual.

Desse modo, embora Freud não tenha pensado em termos de dificuldade de aprendizagem, mas em termos de inibição no pensamento intelectual, de acordo com Santiago (2005), como consequência da abordagem freudiana da inibição, na primeira tópica, podemos compreender a inibição intelectual ou dificuldade de aprendizagem a partir da sexualização do pensamento e, por conseguinte, como resultado do fracasso da ação da inibição sexual, a qual precisa ser refreada para conferir abertura para o trabalho intelectual exitoso, e, por conseguinte para o acesso ao ato de aprender.

\section{Um recorte de uma possível leitura da dificuldade de aprendizagem à luz da segunda tópica}

Freud (1926/1996d), em seu texto Inibição, sintoma $e$ angústia, à luz da segunda tópica do aparelho psíquico, 
argumenta que enquanto um sintoma denota a presença de algum processo patológico, a inibição concerne a uma restrição normal de uma função do eu, não tendo necessariamente uma implicação patológica. Reivindica, portanto, que inibição e sintoma são conceitos que não se encontram no mesmo plano, examinando o primeiro a partir das funções do eu. No entanto, ao longo desse texto, podemos verificar que se de um lado, ao Freud diferenciar inibição e sintoma, podemos ver ratificado o caráter estrutural da inibição como um dado de estrutura, de outro, tal inibição se diferiria da inibição neurótica, pois essa se manifesta como um sintoma nos quadros neuróticos, configurando uma verdadeira renúncia à função: "assim uma inibição pode ser também um sintoma". (Freud, 1926/1996d, p. 91).

Mas, seguindo o percurso de Freud nessa abordagem, ao sustentar, nesse texto, a inibição como um conceito intimamente associado com o da função, e, por conseguinte, conferir uma abordagem da inibição, nesse momento de seu percurso, como a expressão de uma restrição normal de uma função do eu, Freud passa a examinar a função sexual e as do comer, da locomoção e do trabalho profissional, bem como as perturbações dessas funções em diferentes afecções neuróticas.

Sobre a função sexual, esta comporta características típicas de inibições simples que são classificadas como impotência psíquica, embora seja vulnerável a um enorme número de perturbações. Nessa direção, Freud assevera que somente por meio de um processo muito complicado o desempenho normal da função sexual pode ocorrer, podendo, por conseguinte, aparecer distúrbios em qualquer ponto dele. Com isso, ele nos alerta da complexidade de tal desempenho. Ademais, outras perturbações podem surgir a partir da função sexual. No que tange à função de nutrição, Freud nos diz que por causa do desinvestimento da libido, esta função é frequentemente perturbada por uma falta de inclinação para comer, mas uma perturbação no sentido inverso pode tomar lugar: o sintoma de vômitos é concebido como uma defesa histérica contra o comer, e tal recusa deve-se à angústia (sobre essa dimensão de angústia em seu enlaçamento com a inibição e o sintoma, retomar-se-á tal ponto adiante). Já no que se refere à função da locomoção, esta pode ser perturbada por uma falta de disposição ou por uma fraqueza para caminhar.

Quanto à função do trabalho profissional, importa dizer que esta é a que mais queremos privilegiar nesse recorte do texto freudiano de 1926, pois entendemos que $o$ ato de aprender se acomoda na esfera do trabalho intelectual. A novidade que toma lugar na análise freudiana dessa função é que a perturbação dela não se apresenta articulada a um órgão específico. Ademais, sua abordagem sobre o desempenho insatisfatório no trabalho ou a diminuição do prazer sentido nesse trabalho conduz à análise dos mecanismos em jogo nessa renúncia à função operante na inibição.

Embora a abordagem freudiana desses mecanismos ultrapasse o âmbito da função do trabalho profissional, com o intento de centralizar o objeto no centro dessa discussão, que é a dificuldade de aprendizagem enquanto um sintoma, o presente artigo concernirá apenas à análise dos mecanismos operantes nessa renúncia à função da atividade profissional, na qual devemos incluir o trabalho intelectual que acomoda o ato de aprender. Por sua vez, essa conduz às soluções encontradas pelo eu para evitar o conflito tanto com o Isso, quanto com o supereu, nesse referido plano.

Em primeiro lugar, Freud analisa os mecanismos em jogo na renúncia à função operante na inibição da função do trabalho no plano de uma acentuada erotização dos órgãos físicos convocados à ação. "Descobriu-se como ato geral que a função do eu de um órgão fica prejudicada se a sua erotogeneidade - sua significação sexual - for aumentada" (Freud, 1926/1996d, p. 93). Para não entrar em conflito com o Isso, e, assim, evitar a adoção de novas medidas de recalque, o eu renuncia ao desempenho normal dessas funções, que estão dentro de seu campo de ação.

Em segundo lugar, o mecanismo também comportado por essas inibições da função do trabalho profissional no qual se inclui o trabalho intelectual que assenta o ato de aprender, com vistas a evitar o conflito do eu com o supereu irá incluir um elemento próprio da lógica dessa instância e caro para a compreensão da inibição no ato de aprender: a satisfação masoquista. Nessa direção, de acordo com Freud, inibições como as de atividades profissionais revelam também como mecanismo operante a finalidade de autopunição. Para evitar entrar em conflito com os imperativos do supereu, que proíbem êxito e lucro, que poderiam ser trazidos pelo bom desempenho das atividades profissionais, o eu renuncia ao desempenho normal dessas atividades. A operacionalidade desse mecanismo do supereu faz que o sujeito se veja assujeitado a renunciar ao resultado do trabalho sublimado na medida em que tal mecanismo autopunitivo não permite que o sujeito realize qualquer trabalho cujo resultado lhe traga satisfação, êxito e reconhecimento.

Desse modo, a partir do fato de que é possível incluir o trabalho intelectual que contempla o ato de aprender no âmbito das atividades profissionais, Freud, embora não faça uma abordagem explícita da inibição nesse ato de aprender, confere uma indicação de que nessa dimensão da aprendizagem, para não incorrer em conflito com os imperativos do supereu que proíbem o êxito de aceder ao ato conclusivo de aprender e o usufruto dessa aprendizagem, o eu renuncia ao desempenho normal dessas competências cognitivas. "O sujeito trabalha em pura perda, de uma maneira absolutamente alienada, atingindo, por diversos caminhos, o fracasso rendido ao supereu" (Santiago, 2005, p. 133). O sujeito trabalha em um modo de satisfação pulsional masoquista que caracteriza a estrutura do sintoma, procurando apaziguar sua culpa, e, assim, satisfazer o gozo masoquista.

A partir dessa análise, Freud ratifica que se de um lado, inibição e sintoma não se confundem, na medida em que inibição concerne à renúncia e sintoma à formação de compromisso, por outro, isso não impede que certas 
inibições possam ser consideradas sintomas. "As próprias análises clínicas de Freud sobre as inibições intelectuais resgatam esse binômio, ao articular a inibição a um modo de satisfação pulsional específico, que caracteriza a estrutura do sintoma". (Santiago, 2005, p. 133). Modo de satisfação pulsional masoquista, no qual "o sujeito paga com seu trabalho uma sentença ditada por sua própria culpabilidade". (Santiago, 2005, p.133). Portanto, mais uma vez cabe discutir uma possível indicação freudiana no âmbito do nosso interesse que é a dificuldade de aprendizagem na sua vertente sintomática.

Ainda que o presente artigo não esteja privilegiando, em seu recorte, a dimensão da angústia na dificuldade do acesso ao ato de aprender, importa assinalar que nessa análise da inibição na sua relação com o sintoma, Freud inclui uma discussão acerca da função da angústia, argumentando pela existência de uma relação evidente entre a inibição e a angústia, de forma que a angústia introduzida por algumas práticas conduz ao abandono de uma determinada função em algumas inibições. Em outras palavras, Freud diz que a inibição está relacionada à angústia, sendo, portanto, a inibição uma limitação que o eu se impõe para não suscitar a angústia, como, por exemplo, o medo inexplicável de Hans (Freud, 1909/1996c) de sair à rua. Inclusive sobre essa referida criança (Hans), Freud irá asseverar que seu aludido medo inexplicável de sair à rua consistia em um sintoma, ao passo que a incapacidade de sair à rua era uma inibição imposta pelo eu da criança, a fim de não provocar o afeto em questão. A inibição é então apresentada, em seu enlaçamento com o sintoma e com a angústia, como um dispositivo do eu diante de uma situação de perigo desconhecida. De acordo com Nezan (2006), o que causa angústia é o perigo que o eu sinaliza, produzido pela ameaça de uma perda que o deixaria desamparado, um perigo da exigência pulsional que envolve um conflito entre o Isso e o supereu, uma vez que tal satisfação pulsional seria ameaçadora para o eu.

Dessa forma, a possível abordagem freudiana da inibição do trabalho intelectual a partir da sua abordagem da inibição do trabalho de uma maneira geral, de um lado ratifica o que já tinha sido deflagrado nos Três ensaios, a saber, o papel fundamental da inibição como um dado estrutural de inibir a sexualidade quanto a seu objetivo e, por conseguinte, seu laço com a possibilidade de aprender. E, por outro lado, tal abordagem, ao levar em consideração as noções do Isso, do supereu e do masoquismo, revela a dimensão de gozo envolvida na inibição na aprendizagem, que toma lugar quando essa inibição estrutural fracassa.

Acerca disso, Corrêa \& Pinheiro (2013) abordam a inibição concernente à dimensão na qual ela não se confunde com o sintoma, mais especificamente a inibição na aprendizagem na qualidade de dado estrutural, em termos de uma vivência própria do período de latência não circunscrito ao período entre o quinto ano de vida e a puberdade, conforme é apresentado nos Três ensaios, mas a partir das consequências que podemos extrair da abordagem conferida posteriormente por Freud ao período de latência em
Moisés e o monoteísmo (Freud, 1939/1996e). Esse período é compreendido por dúvidas, hesitação e resistência. Ademais, as autoras estabelecem uma aproximação entre tal período de latência pensado a partir do que o texto de 1939 traz de novidade em relação a essa experiência e o tempo para compreender nas aprendizagens. Lacan (1998) fala sobre esse tempo, descrito com os mesmos significantes descritos por Freud ao falar do período de latência no texto de Moisés. É um tempo para compreender que antecede e apoia o momento conclusivo na aprendizagem. Por conseguinte, as autoras concluem que a inibição enquanto um dado estrutural, no âmbito da aprendizagem, trata-se de uma vivência de embaraço que antecede e apoia $o$ ato de aprender.

Ademais, por uma necessidade lógica, é preciso dar um passo nesse exato ponto e dizer que essa abordagem de uma inibição estrutural que antecede e apoia o ponto conclusivo comportado pela lógica do ato de aprender encontra respaldo na significativa contribuição de Lacan ao distinguir o ato da esfera da motricidade, formulando-o como concernente ao exercício do desejo. Para Lacan, a motricidade só tem valor de ato quando se constitui um divisor de águas. Tal formulação lacaniana possibilita tomar os dois mencionados aspectos da abordagem freudiana da segunda tópica: a inibição como uma restrição das funções do eu e o caráter estrutural da inibição, de um modo que termina por inviabilizar a dicotomização entre os dois polos do binário inibição/ato, pois a consideração do trabalho intelectual exitoso requer a consideração do ato de aprender ao qual o acesso requer a necessidade da inibição sexual.

Podemos, a partir dessa contribuição lacaniana, ler em Freud a indicação da existência de um laço entre a inibição e o ato de aprender, já que o ato, como foi dito, na Psicanálise a partir de Lacan, é distinguido da esfera da motricidade e concerne ao exercício do desejo. Ademais, para aprender a criança há de confrontar com a angústia causada pela apreensão da perda, pelo perigo que o eu sinaliza, produzido pela ameaça de uma perda que o deixaria desamparado: a perda do lugar de ser o objeto de gozo do Outro materno, concernente à operação de separação que será abordada posteriormente.

Importa dizer que dentro da referida contribuição de Lacan, na Psicanálise, é justamente nessa matriz freudiana da existência de um enlaçamento entre inibição e ato que concerne ao desejo que esse autor (Lacan, 2005) aborda a inibição, assinalando que, se de um lado, a partir desse texto freudiano, a inibição está na dimensão do movimento, podendo tratar-se da "paralisação do movimento", por outro lado, a inibição nos sugere a "freada".

Mas e quanto às aludidas inibições na aprendizagem que podem ser consideradas sintomas quando envolvem um modo de satisfação pulsional masoquista? É possível encontrar em relação a esse aspecto alguma indicação para o desdobramento dessa questão em Lacan? Sobre isso, o presente artigo argumenta que ainda que não aborde explicitamente a inibição na aprendizagem, a análise de Lacan (1986), em seu seminário $O$ desejo e sua interpretação, 
sobre a inibição de Hamlet, pode legitimamente conferir uma indicação para o desdobramento da dificuldade de aprendizagem na qualidade de sintoma.

Ao trabalhar rigorosamente a tragédia de Hamlet, Lacan (1986) sublinha que essa tragédia traz essencialmente as relações de Hamlet com seu ato de vingar o assassinato do pai, ato do qual Hamlet depende em sua posição global, mas que fica procrastinado, paralisado, adiado para o dia seguinte. Importa então nesse ponto do presente artigo falar, ainda que minimamente, da referida tragédia de Shakespeare, na própria medida em que a inibição de Hamlet constitui um verdadeiro paradigma da inibição neurótica, da qual a inibição, enquanto um sintoma, na aprendizagem faz parte.

\section{Dificuldades de aprendizagem e o estatuto do saber no Outro}

Hamlet é uma tragédia de Shakespeare sobre o assassinato do pai de Hamlet por seu irmão Claudius, que após a morte do rei casa-se com sua mãe e se torna o novo monarca. O pai de Hamlet é apresentado na peça como um pai excessivamente idealizado, o que veremos mais adiante. Após sua morte, o fantasma do pai aparece para Hamlet contandolhe tudo acerca das circunstâncias de seu assassinato e quem o matou. Tal fantasma do pai demanda de Hamlet a vingança por esse assassinato, mas a tragédia traz o príncipe dinamarquês completamente inibido, paralisado diante desse ato de vingar o assassinato do pai. Lacan (1986), ao tomar essa peça em consideração, nos indica ser Hamlet o paradigma da inibição neurótica. Ademais, ao nos dizer que no cerne da inibição de Hamlet há uma comunhão de saber entre Hamlet e seu pai na medida em que ambos sabem demais acerca do assassinato, nos indica que no cerne da inibição neurótica - na qual podemos incluir a inibição, enquanto sintoma, na aprendizagem - pode haver um Outro que sabe demais.

A partir de $O$ tempo lógico e a asserção da certeza antecipada (Lacan, 1998), compreendemos que o ato encerra em sua estrutura o instante de ver, o tempo para compreender e o momento de concluir. Quer-se assinalar nesse ponto a experiência concernente ao referido "tempo para compreender" que consiste em uma das etapas lógicas de todo e qualquer processo de assimilação humana. Uma vivência lógica, como também já foi dito, caracterizada por dúvidas, hesitação, resistência e embaraço que antecede e apoia a urgência do momento de concluir, arrancando, pois, o sujeito da inibição para que ele possa prosseguir e fazer ato na vida.

Como corolário, podemos dizer que se em Hamlet se trata de uma paralisação diante do ato a partir da protelação do pensamento em Hamlet, típica do obsessivo, torna-se plausível pensar a inibição neurótica - e com ela a inibição na aprendizagem ou dificuldade de aprendizagem na qualidade de um sintoma - como uma paralisação no tempo para compreender, uma paralisação que impede o sujeito de prosseguir em seu percurso e aceder ao ato de aprender.
Ademais, Lacan (1986) argumenta que o problema de Hamlet, expresso por seu “to be or not...?", é o de encontrar o lugar tomado pelo que lhe disse seu pai na condição de fantasma, que ele foi surpreendido pela morte na "flor de seus pecados". "Trata-se para ele de encontrar o lugar tomado pelo pecado do Outro, o pecado não pago. Aquele que sabe é, ao contrário de Édipo, alguém que não pagou o crime de existir" (Lacan, 1986, p.10). E ele, Hamlet, não pode nem pagar ele mesmo, tampouco deixar a dívida aberta.

No fim das contas, ele tem que fazer com que a paguem. Mas, nas condições em que se encontra, o golpe passa através dele mesmo. Se ele atinge finalmente o criminoso, é com a mesma arma que acaba de feri-lo mortalmente. (Lacan, 1986, p.10)

Isso nos interessa porque diz respeito a um ponto fundamental para o presente artigo: a comunhão de saber entre Hamlet e o seu pai. Ambos sabem demais. É exatamente essa comunhão que paralisa Hamlet diante de seu ato. Na problemática da assunção por Hamlet de seu ato, trata-se de um Outro que sabe demais.

Desde o início de seu percurso, Freud se depara com a ordem inconsciente no que concerne ao saber que a análise visa a circunscrever mesmo sem ter articulado esse saber inconsciente como tal. Logo, podemos ver, desde essa época, a existência de algo que o paciente sabe, mas não sabe que sabe que concerne ao saber inconsciente. Algo que determina os estados subjetivos para além da consciência que o sujeito possa ter dele ou de seus efeitos, estando, dessa maneira, fertilizado o solo de onde nascerá a teorização freudiana que se desenvolverá no sentido de formular mais tarde o desejo inconsciente que habitará o sujeito psicanalítico (Lo Bianco, 2003).

A Psicanálise desde Freud veio anunciar que o inconsciente no que habita a linguagem, comporta um saber que é um corte em relação ao saber socrático por não ser um saber consciente e transparente para si mesmo (Lacan, 1992). Antes, o saber que o inconsciente habita é um saber que não se sabe, justamente por ser inconsciente. Esse saber inconsciente se baseia no significante como tal e se irrompe por um instante pela fenda do inconsciente, trazendo à luz a experiência de um desejo indestrutível inconsciente.

Nessa direção, a aprendizagem se sustenta habitualmente na suposição de que o Outro sabe. Entretanto, na experiência clínica com casos de crianças com dificuldades de aprendizagem ou inibição na aprendizagem, podemos verificar padecimentos nas aprendizagens que introduzem outras vicissitudes na relação do sujeito ao saber, nos conduzindo para um desdobramento da problemática desse estatuto do saber no Outro, no acesso ao ato de aprender. Entre essas vicissitudes mencionadas na introdução, o presente artigo argumenta que nesse campo da inibição na aprendizagem também podemos pensar em termos de um fracasso do ponto de falta nesse saber ser sustentado na sua impossibilidade. Dimensão formulada a partir do que a experiência clínica muitas vezes indica, que 
ao contrário de um Outro que não sabe, há quadros em que o Outro sabe demais - pai idealizado, do qual o referido pai de Hamlet é o paradigma.

Lacan (1992), em seu seminário sobre a transferência, assevera que, enquanto no nível do Édipo, o pai é morto sem mesmo que o herói o saiba, no nível do Hamlet, "não é 'ele não sabia' que se deve dizer dele, mas 'ele sabia'. Não somente 'ele sabia', mas este fator intervém na incidência subjetiva que nos interessa, a do personagem central, Hamlet" (Lacan, 1992, p. 313). Este saber é um pai condenado quem o revela, "o ghost, aquele que, para além da morte, revela ao filho que foi morto, como e por quem" (Lacan, 1992, p. 276), de tal modo que ele soube muito sobre isso. De acordo com Lacan, o pai de Hamlet é um pai condenado, e isso quer dizer que para além da fantasia da danação eterna o pai começa aqui a saber. "Decerto ele não sabe todo o mecanismo, mas sabe dele mais do que se crê. Sabe, em todo caso, quem o matou, e como foi morto" (Lacan, 1992, p. 277). Nessa direção, Lacan assinala a dimensão do Ideal no pai de Hamlet qualificado como o Ideal do cavaleiro do amor cortês. "Esse homem atapetava de flores o caminho a ser percorrido pela rainha. Esse homem afastava de seu rosto, diz-nos o texto, o mínimo sopro de vento" (Lacan, 1992, p. 277). Segundo Lacan, é nessa estranha dimensão onde permanece, e unicamente para Hamlet, a eminente dignidade de seu pai e a fonte sempre fervilhante de indignação em seu coração. Por ser o pai uma espécie de Ideal de homem, em lugar algum esse pai é evocado como rei; é discutido como autoridade. Nesse ponto, importa marcar que de fato se esse pai é um pai idealizado demais, a autoridade dele está degradada, pois a autoridade do Outro que está articulada à transmissão e, portanto, à castração, se sustenta na contramão dessa excessiva idealização.

Importa dizer que enquanto de um lado o Outro é instituído por Lacan (1996, p. 130), como o lugar do saber, de outro lado, ele nos indica na mesma referência que o Outro castrado sabe, mas nada sabe da verdade do desejo, da castração que concerne a um ponto opaco no seu saber. E é esse ponto de falta no seu saber que toca na verdade da castração que o Outro transmite ao sujeito para que ele possa inventar um saber "a partir de pedaços de real" (Vidal, 1999, p. 27). Esse ponto de falta no saber do Outro introduz o encontro tíquico (tiquê), isto é, o encontro sempre traumático do sujeito com o enigma de seu desejo, por representar um ponto de oposição à possibilidade de simbolização (Pisetta, 2012), que introduz a operação de separação, uma das operações de constituição do sujeito no campo do Outro (Lacan, 1988).

\section{As operações lógicas da constituição do sujeito e inibição}

De acordo com Lacan (1988), sendo o inconsciente estruturado como uma linguagem, tendo ele a estrutura de significantes, o inconsciente é o Outro por excelência. Sendo o sujeito efeito de significante, ele se constitui nesse campo do Outro. Tal "relação do sujeito ao Outro se engendra por inteiro num processo de hiância" (Lacan, 1988, p. 196), cujos processos devem ser articulados como circulares e por isso dissimétricos, mas sem reciprocidade.

No entanto, essa partida do inconsciente tem como característica seu paradoxal fechamento instituído pela pulsação temporal que consiste no aparecimento do sujeito como efeito de significante para logo em seguida desaparecer. Daí se depreende o caráter evanescente do inconsciente e de seu sujeito. Em termos freudianos, podemos pensar tal operação pela noção do recalque, reivindicada ao nos dizer que a suspensão do recalcado que concerne ao inconsciente é sempre e apenas temporária. $\mathrm{O}$ inconsciente abre-se para logo em seguida se fechar. A operação de alienação implica uma cisão original do sujeito que o divide entre $S_{1}$ e $S_{2}$. Enquanto o primeiro significante designa o sujeito, seu ser, e não lhe dá sentido algum, o segundo significante lhe dá sentido ao preço de produzir a afânise do sujeito, o apagamento do seu ser.

Dentro desse contexto, Lacan argumenta que o erro de Piaget é concerne ao que ele afirma ser o "discurso egocêntrico da criança", porque, para ele, essa noção é um contrassenso, pois "a criança, nesse famoso discurso que podemos registrar num gravador, não fala para si, como dizem" (Lacan, 1988, p. 197). Com isso, Lacan não coloca em dúvida, de modo nenhum, que de fato, como Piaget argumenta, a criança nesse chamado "discurso egocêntrico" não se dirige a outro, em termo de "uma repartição teórica que se deduz da função do 'eu' e do 'tu”' (Lacan, 1988, p. 197). Mas, para Lacan, o fato de a criança nesse discurso não estar na dimensão do diálogo não exclui uma outra relação dela com o Outro simbólico da linguagem que está para além de toda e qualquer relação dual; não exclui a relação dela com o Outro como um lugar simbólico para onde ela se dirige para escolher os significantes que lá estão, e por isso seu discurso não é "egocêntrico", mas a partir do Outro e também endereçado ao Outro, na medida em que, por exemplo, todos os seus "porquês" visam à colocação em prova desse Outro como suposto lugar do saber.

Nessa direção, Lacan reporta-se à lógica simbólica que, engajada no projeto de evitar mal-entendidos, vai falar dos dois tipos de "ou" na linguagem, propondo um recurso para o embaraço colocado pela ambiguidade da palavra "ou". O primeiro significado é o "ou inclusivo" que tem o sentido de "um ou outro, possivelmente ambos" (Copi, 1978, p. 229). O segundo significado é o "ou exclusivo", que possui o significado de "pelo menos um e no máximo um" (Copi, 1978, p. 229).

Quanto ao referido recurso da lógica simbólica para evitar equívocos advindos dessa ambiguidade do "ou", ele é encontrado na língua latina, uma vez que a lógica simbólica argumenta que, embora as disjunções sejam ambiguamente expressas nas línguas modernas, tal ambiguidade não existe no latim porque a língua tem duas palavras diferentes que correspondem aos nossos dois sentidos distintos da palavra "ou". Enquanto a palavra latina "vel" expressa a 
disjunção débil ou inclusiva, a palavra latina "aut" corresponde ao "ou" em seu sentido exclusivo.

A novidade trazida por Lacan nesse retorno à lógica simbólica no que concerne aos dois tipos de "ou" é que existe ainda um terceiro "ou", não contemplado por tal lógica, que ele chama de "ou" alienante ou "vel" alienante. Não se trata de uma invenção arbitrária sua. Trata-se de um "ou" que Lacan extrai da linguagem, presente em escolhas forçadas do tipo "a bolsa ou a vida!". No que concerne ao exemplo, se o sujeito escolhe a bolsa, ele perde as duas. Se ele escolhe a vida, ele tem a vida decepada da bolsa. Lacan nos diz que, dessa problematização, podemos formular que não há bolsa sem a vida, mas também não há vida com bolsa.

Nesse tipo de "ou" alienante encontrado por Lacan na linguagem, a alienação ocorre porque o que há em jogo é uma escolha forçada de pura perda. É exatamente esse tipo de escolha, tendo em seu cerne o "vel" alienante que Lacan argumenta consistir uma das duas operações em jogo na constituição do sujeito no campo do Outro: a escolha entre o ser e o sentido. De maneira análoga a "a bolsa ou a vida!", o sujeito vê-se no campo do Outro forçado a uma escolha de pura perda entre o ser ou o sentido. Se escolhermos o ser, o sujeito desaparece, nos escapa, cai no não senso. Se escolhermos o sentido, "o sentido só subsiste decepado dessa parte de não senso que é, falando propriamente, o que constitui na realização do sujeito, o inconsciente" (Lacan, 1988, p. 200).

Como corolário dessa operação de alienação, o desejo do sujeito é o desejo do Outro. No entanto, a constituição do sujeito no campo do Outro não se esgota na operação de alienação. Se assim fosse, estaríamos no domínio do puro determinismo psíquico, do "seja feita a tua vontade" (Rabinovich, 2000). Dizer que o desejo do sujeito é o desejo do Outro é dizer que existe uma alienação estrutural do desejo do sujeito ao desejo do Outro, que, por ser estrutural, a liberdade total dessa alienação é a morte. Mas isso não quer dizer que não haja uma saída do "vel" da alienação que confira uma "margem de liberdade" para que o sujeito possa colocar algo de seu naquilo que herdou do Outro. Tal margem de liberdade é conferida pela segunda operação em jogo na constituição do sujeito no campo do Outro, que é a operação de separação.

Essa segunda operação de separação, saída do "vel" da alienação por excelência, "termina a circularidade da relação do sujeito ao Outro" (Lacan, 1988, p. 202), mas demonstrando uma torção essencial. Ela está fundada na subestrutura lógica da interseção que surge do recobrimento de duas faltas. O enigma do que o Outro deseja se destaca dos intervalos do seu discurso e "é apreendido pelo sujeito naquilo que não cola, nas faltas do discurso do Outro" (Lacan, 1988, p. 203). Nessa direção, Lacan argumenta que todos os já referidos "porquês" da criança visam, ao invés de uma demanda interminável de respostas, a uma sustentação do enigma do desejo do adulto, a "uma colocação em prova do adulto, um "por que será que você me diz isso?" (Lacan, 1988, p. 203). Essa lacuna encontrada no discurso do Outro é aquilo que a criança encena ao jogar com sua própria falta - se ele pode faltar ao Outro. O sujeito responde ao ponto de falta no saber do Outro que introduz o enigma de seu desejo, operando com sua própria perda como objeto de gozo do Outro, confrontando, por conseguinte, com a angústia. Com isso, Lacan ressalta a função separadora do desejo, na própria medida em que, temos primeiro falta de sujeito, depois perda do sujeito como objeto de gozo do Outro. Passagem da falta à perda, que poderá tornar-se causa.

É diante do enigma que o desejo do Outro introduz que é possível que um saber faltante se invente, possibilitando, por conseguinte, uma abertura para a aprendizagem, na medida em que o excesso de embaraço da criança com esse enigma, com a dimensão do saber no Outro, quando, por exemplo, esse saber é excessivamente idealizado, pode colocar como efeito esse embaraço excessivo no nível do conhecimento. Para Vidal (1999), foi exatamente a falta desse saber que tanto Anna Freud como Melanie Klein desconheceram. Enquanto, para a primeira, é necessária uma educação para aceder ao saber, para a segunda, o saber, assim como para o cientista, já está dado, cabendo ao analista descobri-lo. "O saber não está aí, ele falta e é preciso inventá-lo" (Vidal, 1999, p. 2324). Para que a criança aceda a um saber inventado, ela precisa se confrontar com o buraco do saber no Outro, com a inconsistência do pai e, por conseguinte, com o enigma advindo desse furo no Outro.

Nessa direção, argumenta-se que é exatamente nessa perspectiva freudiana da existência de um enlaçamento entre inibição e ato que concerne ao desejo que Lacan (2005) aborda a inibição. Ele assinala que, se de um lado, a partir desse texto freudiano, a inibição está na dimensão do movimento, podendo tratar-se da "paralisação do movimento", por outro lado, a inibição nos sugere a "freada". De acordo com Santiago (2005), pautado rigorosamente no bloqueio da função, aspecto central da abordagem freudiana de 1926 acerca da inibição, Lacan, no seminário $A$ angústia (2005), ao desenvolver uma reflexão acerca da função da causa do desejo, privilegia, portanto, como a função em jogo na dimensão da inibição, a função do desejo, que, ao ter sua causa bloqueada, provoca uma série de efeitos sintomáticos no sujeito, entre os quais a própria inibição neurótica, dentro da qual se encontra a inibição na aprendizagem.

Porém, a inibição também é lida como uma ação que precede $o$ ato. Ressalta-se, portanto, da leitura lacaniana sobre a inibição a ratificação da dimensão estrutural da inibição deflagrada por Freud. Tal dimensão da inibição se dá a partir do encontro sempre traumático do sujeito infantil no percurso de suas investigações sexuais com o ponto de falta no saber do Outro que introduz o já referido enigma de seu desejo: "Ele me diz isso, mas o que ele quer dizer?" (Lacan, 1988), introduzindo a abordada operação de separação, cujo resto caído é o objeto $a$ que "circunscreve um tempo intermediário entre gozo e desejo". (Vidal, 1988, p.28). Esse objeto perdido constitui "condição, digamos, 
absoluta, do trabalho da prova da realidade e, concomitantemente, do surgimento do desejo". (Vidal, 1988, p. 28). Dessa forma, ao articular Lacan com Freud, pensamos que a inibição estrutural articulada à operação de separação ao incidir sobre a tendência que conduz o aparelho na direção do gozo alucinatório que em si mesmo é inerte funda a causa do desejo, separando gozo e desejo. O hiato produzido pela falta de coincidência entre o objeto alucinatório e o objeto reencontrado "é o que funciona como causa do desejo" (Santiago, 2005, p. 146) e demarca a função estrutural da inibição que nos primeiros textos freudianos se apresenta como freio sobre a tendência que conduz o aparelho ao gozo alucinatório, o que ocorre simultaneamente à prova do surgimento do desejo, ou seja, à prova da realidade condicionada pela perda do objeto e que por isso consiste sempre em reencontrá-lo.

A colocação em ato da perda do objeto no lugar da causa a partir da ação da inibição funda a causa do desejo, mas a falha da efetividade dessa ação inibitória estrutural implica a permanência em jogo do gozo articulado à dimensão ineliminável do Ideal, do pai idealizado, do Outro que sabe demais, que, ao escamotear o real do ponto de falta do saber no Outro, encontrado traumaticamente pela criança, bloqueia, obstrui a causa do desejo. Dizendo mais explicitamente, de acordo com Lacan (2005), nesse nível de escamoteamento do real pelo Ideal, a causa do desejo não se dá a conhecer. Somente ao objeto $a$ operar como causa perdida, como vetor da operação de separação, é que a certeza concernente à conclusão é veiculada, e o sujeito pode aceder ao ato (no caso, ao ato de aprender) em vez de ficar paralisado no tempo para compreender que comporta dúvidas, hesitação e resistência. Nesse nível de escamoteamento do real pelo Ideal, há protelação do pensamento, paralisação diante do ato, a precipitação própria do acting e, inclusive, passagem ao ato, mas não o ato, constelação da qual a tragédia shakesperiana de Hamlet é o paradigma.

\section{Learning difficulty and other's idealized knowledge}

Abstract: This article discusses, from the psychoanalytic approach of Freud and Lacan, the relevant problem of learning difficulties when they come in symptomatic sense. It argues that on one hand learning is sustained on the assumption that the Other knows, but on the other hand we can verify within the cases of learning difficulties vicissitudes that call into question the relationship between subject and knowledge and that guide us to another dimension of this problematic status of knowledge in the Other. In this field, we can only verify one Other who does not know or can also emerge an Other whose knowledge is excessively idealized? In this sense, this article discusses the role of the Ideal in learning disabilities.

Keywords: learning difficulties, inhibition, ego ideal, Sigmund Freud (1856-1939), Jacques Lacan (1901-1981).

\section{Difficulté d'apprentissage et le savoir idéalisé dans l'autre}

Résumé: L'article aborde, à partir de l'approche psychanalytique de Freud avec Lacan, la problématique concernant les difficultés d'apprentissage présentées en dimension symptomatique. II est soutient que, d'un part, I' apprentissage est basée sur I'hypothèse que l'Autre sait, mais d'autre part, on peut voir dans les contextes de difficulté d'apprentissage des événements qui remettent en question la relation du sujet avec le savoir, qui nous conduise à une autre dimension de cette question du statut du savoir chez l'Autre. S'agit-il, dans ce domaine, seulement d'un Autre que ne sait pas, ou peut-il se produire également un Autre dont le savoir est trop idéalisé ? En ce sens, l'article traite de la dimension de l'Idéal présente dans la difficulté d'apprentissage.

Mots-clés: difficulté d'apprentissage, inhibition, moi idéal, Sigmund Freud (1856-1939), Jacques Lacan (1901-1981).

\section{Dificultad de aprendizaje y saber idealizado en el otro}

Resumen: El artículo plantea, a partir del abordaje psicoanalítico de Freud y Lacan, la relevante problemática de las dificultades de aprendizaje cuando se presentan en la vertiente sintomática. Para ello, argumenta que de un lado el aprendizaje sostiene la suposición de que el Otro sabe, pero, por otro lado podemos verificar en los cuadros de dificultad de aprendizaje vicisitudes que ponen en cuestión la relación del sujeto al saber que nos conducen a otra dimensión de esa problemática del estatuto del saber en el Otro ¿Se trata en ese campo solamente de un Otro que no sabe o puede emerger también un Otro cuyo saber es excesivamente idealizado? En este sentido, el artículo trata de la dimensión del Ideal presente en las dificultades de aprendizaje.

Palabras clave: dificultad de aprendizaje, inhibición, ideal del ego, Sigmund Freud (1856-1939), Jacques Lacan (1901-1981). 


\section{Referências}

Cabral, E., \& Sawaya, S. M. (2001). Concepções e atuação profissional diante das queixas escolares: os psicólogos nos serviços públicos de saúde. Revista Estudos Psicológicos, 6(2), 143-155.

Copi, I. M. (1978). Introdução à lógica. São Paulo, SP: Mestre Jou.

Corrêa, C. R. G. L., \& Pinheiro, G. S. (2013). Período de latência e tempo para compreender nas aprendizagens. Revista Psicologia em Estudo, 18(1), 61-69.

Freud, S. (1996a). Três ensaios sobre a teoria da sexualidade. In S. Freud, Edição standard brasileira das obras psicológicas completas de Sigmund Freud (J. Salomão, trad., vol. 7, pp. 118-229). Rio de Janeiro: Imago. (Trabalho original publicado em 1905)

Freud, S. (1996b). Sobre as teorias sexuais das crianças. In S. Freud, Edição standard brasileira das obras psicológicas completas de Sigmund Freud (J. Salomão, trad., vol.9, pp. 211-228). Rio de Janeiro: Imago. (Trabalho original publicado em 1908)

Freud, S. (1996c). Análise de uma fobia em um menino de cinco anos. In S. Freud, Edição standard brasileira das obras psicológicas completas de Sigmund Freud (J. Salomão, trad., vol. 10, pp. 11-131). Rio de Janeiro: Imago. (Trabalho original publicado em 1909)

Freud, S. (1996d). Inibição, sintoma e ansiedade. In S. Freud, Edição standard brasileira das obras psicológicas completas de Sigmund Freud (J. Salomão, trad., vol. 20, pp. 79-169). Rio de Janeiro: Imago. (Trabalho original publicado em 1926)

Freud, S. (1996e). Moisés e o monoteísmo. In S. Freud, Edição standard brasileira das obras psicológicas completas de Sigmund Freud (J. Salomão, trad., vol. 23, pp. 19-150). Rio de Janeiro: Imago. (Trabalho original publicado em 1939)
Lacan, J. (1986). Hamlet por Lacan, 1959-60 (M. T. Berlinck \& M. C. R. Magalhães, trads.). Campinas, SP: Liubliú.

Lacan, J. (1988). O seminário, livro 11: os quatro conceitos fundamentais da psicanálise, 1964 (M. D. Magno, trad.). Rio de Janeiro: Jorge Zahar.

Lacan, J. (1992). O seminário, livro 8: a transferência, 196061 (D. D. Estrada, trad.). Rio de Janeiro: Jorge Zahar.

Lacan, J. (1996). O seminário, livro 20: mais, ainda, 1972-73 (M. D. Magno, trad.). Rio de Janeiro: Jorge Zahar.

Lacan, J. (1998). O tempo lógico e a asserção de certeza antecipada, 1945. Escritos (V. Ribeiro, trad., pp. 197213). Rio de Janeiro: Jorge Zahar.

Lacan, J. (2005). O seminário, livro 10: a angústia, 1962-63 (V. Ribeiro, trad,). Rio de Janeiro: Jorge Zahar.

Lo Bianco, A. C. (2003). Sobre as bases dos procedimentos investigativos em Psicanálise. Revista Psico, 8(2), 115124.

Mendes, E. R. P. (2011). Pulsão e sublimação: a trajetória do conceito, possibilidades e limites. Revista Reverso, 33(62), 55-68.

Nezan, M. B. C. (2006). Inibição intelectual: manejos clínicos. Estilos da Clínica, 11(20), 95-103.

Pisetta, M. A. A. M. (2012). Inconsciente e transferência: perspectivas na clínica. Estudos de Psicologia, 29(1), 95-103.

Rabinovich, D. S. (2000). O desejo do psicanalista. Rio de Janeiro, RJ: Companhia de Freud.

Santiago, A. L. B. (2005). A inibição intelectual na psicanálise. Rio de Janeiro, RJ: Jorge Zahar.

Vidal, E. (1988). Comentários sobre 'Die Verneinung. Revista da Letra Freudiana, 8(5), 16-31.

Vidal, E. (1999). Um outro saber. Revista da Letra Freudiana, 17(23), 21-27.

Recebido: $21 / 08 / 2013$

Revisado: 01/07/2014

Aceito: 23/09/2014 


\section{Erratum - Dificuldade de aprendizagem e saber idealizado no Outro}

No artigo Dificuldade de aprendizagem e saber idealizado no Outro publicado no periódico Revista Psicologia USP, volume 26, número 1, onde se lia:

"Crístia Rosineire Corrêa"

leia-se:

"Crístia Rosineiri Gonçalves Lopes Corrêa" 